The Sustainable City XIV 31

\title{
SUSTAINABLE URBANIZATION IN PATAGONIA TO ADDRESS CLIMATE CHANGE AND COUNTRY NDCS: A CASE STUDY OF A MIXED COASTAL URBANIZATION PROJECT
}

\author{
DANIEL PEREZ ${ }^{1}$, LAURA PEREZ ${ }^{1}$, ADRIANA PEREZ ${ }^{1} \&$ JORGE ABRAMIAN ${ }^{2}$ \\ ${ }^{1}$ Refugio de los Lobos S.A., Argentina \\ ${ }^{2}$ Civiltec, Argentina
}

\begin{abstract}
The current energy matrix in Argentina is highly dependent on fossil sources, with a low contribution from renewable sources. Argentina adhered to the Paris agreements of 2015 for the reduction of $\mathrm{CO}_{2}$ emissions. Therefore, the commitment to comply with the implementation of the NDC (National Determined Contributions) objectives mainly related to the generation of renewable energy and efficiency. This project aims at capacity building to support energy transitions towards low emissions and economic, ecological, resilient, and inclusive urbanizations. As the population grows, the quality of ecosystems and the urban environment correlates to public health, where the balance between demographics reduces pressure on the natural environment, creating and improving the conditions of sustainable urbanizations to provide greater protection of biodiversity and the natural environment. The project is a possible scalable model of sustainable urbanization development in arid coastal environments, addressing issues of land restauration, clean energy generation, reducing fossil fuel dependency, waste and water management, circular economies, and bioclimatic architecture for energy efficiency to combat climate change. A case study is presented as the first mixed eco-urbanization project in Patagonia, designed to minimize the impact on the environment and the living beings; combining rewilding of eroded coastal areas, for the creation of natural landscape reserve areas, and public areas, including an interpretation of scientific research and education centre; and other facilities. All these combined, promoting socialization and exchange, benefit the entire community. The multithemed project would be unprecedented in the region. It restores an area eroded for decades by quarries, landfills from human misuse, ordering a public-private space, generation of productive activities, direct investment, and employment. It enhances landscape conditions to support tourist resources and the beauties of the Patagonian region.
\end{abstract}

Keywords: sustainable urbanization, arid environments, eco-urbanization, mixed urbanization, Patagonia, urban planning, eroded coastal, energy transitions, dune, coastal restauration.

\section{INTRODUCTION}

Climate change as global effect imposes a systemic risk to economies, people, and communities. In the future, the consequences could be even worse, provided mitigation measures are not implemented [1]. Climate risk management problem in the finances of a country becomes an integral part of the solution for sustainable economic development [2].

Compliance to the climate goals of the Paris Agreement requires significant investments, where access to finance and investment programs are necessary for long-term recovery. The COVID 19 pandemic adds to this challenge and highlights the need for investments in green recovery to minimize climate risk, favouring energy transitions [3]. As well as to contribute to the development of mechanisms for the participation of the private sector in the formulation and implementation of climate policies with a focus on the implementation of country (NDCs) mitigation actions [4]. It promotes the exchange of experiences and good practices, joint learning, and collaboration to address common challenges, by developing strategies, projects, financing mechanisms, and technical advice. 
This project specifically addresses the following country NDCs:

- Energy: renewable energy and home distribution, energy efficiency;

- Ecological restoration in degraded environments;

- Mobility: urban planning to facilitate walking, cycling.

\section{DEMOGRAPHIC GROWTH AND SUSTAINABLE DEVELOPMENT}

Patagonia comprises vast territories of land. However, due to unplanned growth during decades, cities, and urban conglomerations resulted in highly concentrated areas with poor connectivity and public services. The nearby coastal city of Comodoro Rivadavia had its origins in oil exploitation. Since the early 1900, it has grown through oil camps to house workers from abroad who came seeking opportunities following rapid economic growth. For this reason, the city suffers of lack of long-term urban planning and grew in patches, resulting in disconnected highly dense neighbourhoods, often facing with their backs to the sea, beauties of natural landscapes [5].

In line with the objectives of the UN (sustainable cities) and the country NDCs towards the reduction of emissions, mitigating climate change, the use of energy through clean sources is selected. It promotes the use of residential renewable energies with possible subsequent reinjection into the electricity grid through the new law on the Promotion of Distributed Generation of Renewable Energy Integrated to the Public Electricity Grid [6].

From its inception and throughout the entire process, the urbanization project is designed to provide solutions to both urban planning and the ordering of public and private space, with access to public areas and the focus on linking with the community and improving services. It contemplates a low density of spaces for residences in a Patagonian environment and in a coastal environment, with the rewilding of native vegetation in the eroded coastal area (Fig. 1).

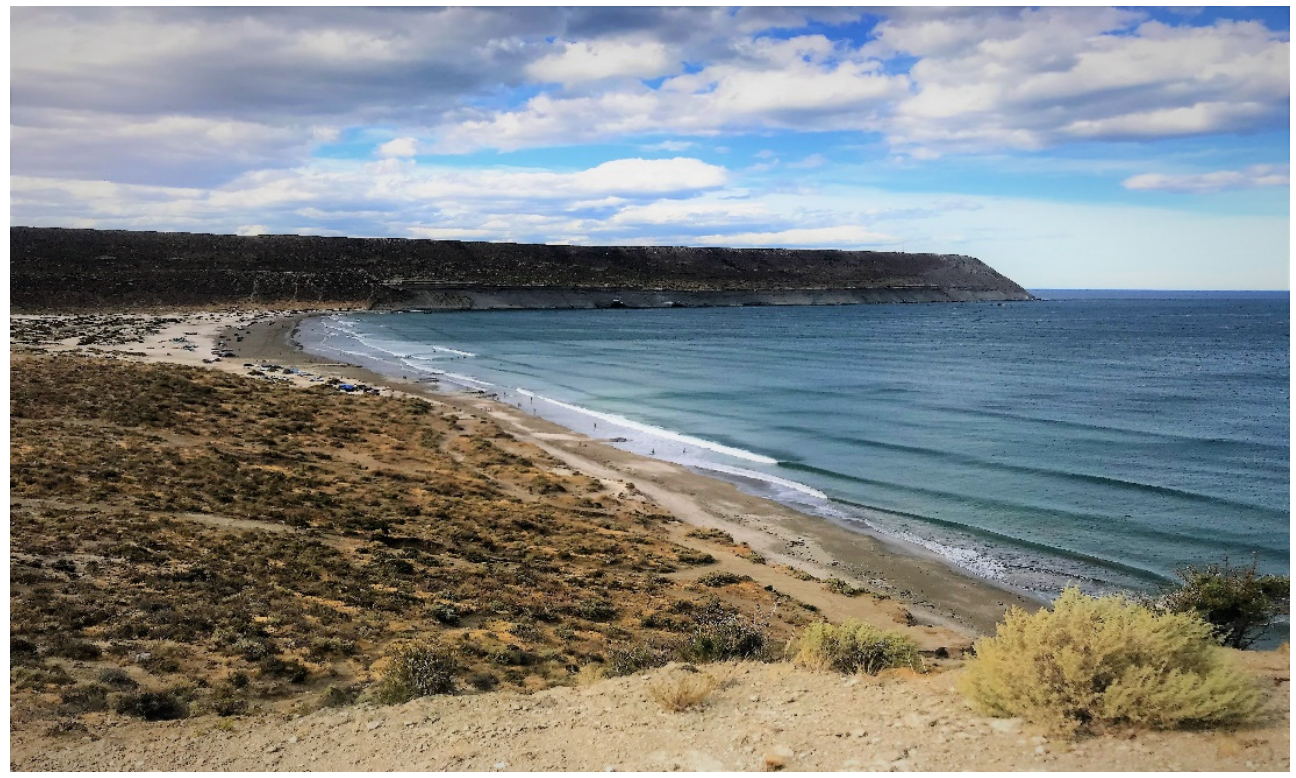

Figure 1: Image showing the future location of the project and eroded coastline at the end. 


\section{DESCRIPTION}

Located on the east coast of Patagonia, at the parallel $45 \mathrm{degS}$, in the province of Chubut, Argentina. The project was conceived under the concept of Mixed Urbanization based on sustainability, accessibility, and innovation, integrating spaces for housing, public area, and restored landscape reserves. The urban master planning is based on a landscape strategy incorporating the characteristics of geomorphology of the existing terrain and natural environment. It aims to improve the quality of life in an arid Patagonian context, the preservation of the ecosystem and the generation of renewable energy in common and residential areas. Commitment to preserve the characteristics of the environment is a priority for the project, preservation of the natural environment through the efficient use of energy, resources and waste management, bioclimatic architecture in favour energy savings. It applies concepts of ecological urbanization linked to sustainable, green, environmentally conscious bioclimatic architecture, designing for energy efficiency. It is proposed a public recreation area, guaranteeing free access to the beach, recreation areas, and facilities for scientific research related to Patagonian biodiversity, coastal studies, and environment education, among others. All in a natural, and orderly environment available to the entire community. At the same time, contained by an urban framework of private houses and private spaces where residents assume commitments such as the use of renewable energy, recycling of waste and the control of effluents, among others, respecting and enhancing the natural landscape. It aims to provide collective and inclusive solutions. To achieve this, a team of specialists in each discipline provides support and guidance to residential users.

\subsection{Issues addressed}

The project addresses the following local and regional issues:

- Population growth, concentration in large cities, high density

- Land and coastline affected by landfills and garbage dumps

- Lack of awareness on environmental, coastal erosion and energy issues

- Dune and coastal protection eroded by anthropogenic use and increasingly aggressive weather

- Regional housing shortages in a context of nature and sea

- Lack of potable water as a resource in this arid Patagonia region

- High dependence on fossil fuels for energy consumption

- Limitations and interruptions in the local electrical distribution network

- Irrational use of energies; cultural and low efficiency in constructions

- High dependency of fossil extraction, poor diversification of the local economy

- Inadequate policies to support green development

- Lack of awareness, government policies and support on sustainable development and measures to combat climate change.

\section{RECREATING LANDSCAPE}

In the year 1985 the founder of the project and owner of the land that hosts a colony of sea lions, due to the constant aggression by hunters to fauna, donated this part of the land with the purpose of conservation of the ecology, flora, fauna, and allowing tourist development converted in the Protected Natural Area Punta Marques, administered by the government of the province. 


\subsection{Dune and coastal regeneration}

The adjacent coastal area of Belvedere beach suffered human misuse for decades and mitigation measures had to be taken to restore and preserve the coastal environment and ecosystem [7]. The sensitivity of these environments to erosion is high due to the poor structure of the soils predisposing them to wind and water erosion [8]. After researching and analyses, it was decided to invest in a coastal bioengineering solution. The objective of the project - never developed on a Patagonian beach - was to rebuild the sand dune that serves as a coastal protection system (Fig. 2). Once created, this system behaves dynamically changing according to the action of the wind and the sea. Reconstruction of sand dunes with compatible local sand was considered of high interest and a unique experience in the southeast Atlantic coastline of Argentina. As a contribution in recompositing a decayed ecosystem, preventing from being exposed to human behaviour, once reforested with native species for soil fixing, this area will be dedicated to landscape and coastal reserve for future preservation. With respect to vegetation, it is proposed to maintain the physiognomic-floristic attributes of the dominant plant communities [9]. The reconstruction of dunes provides a dual purpose:

1. Ensure availability of sand for a natural dynamic coastal process generated by the wind and sea actions

2. An extended section of the dune beach fill provides long term protection, extending the berm and dry beach to contribute with additional protection of the dune to further mitigating, and even mitigate climate change effects of rising sea levels (Fig. 3).

The immense value that sand dunes represent in terms of shoreline stability and coastal protection is widely recognized and many countries have undertaken projects to rebuild and preserve existing dunes. Through this effort, a technical solution is offered that combines natural landscape and environmental improvement, with the use of sand material from the same terrain source.

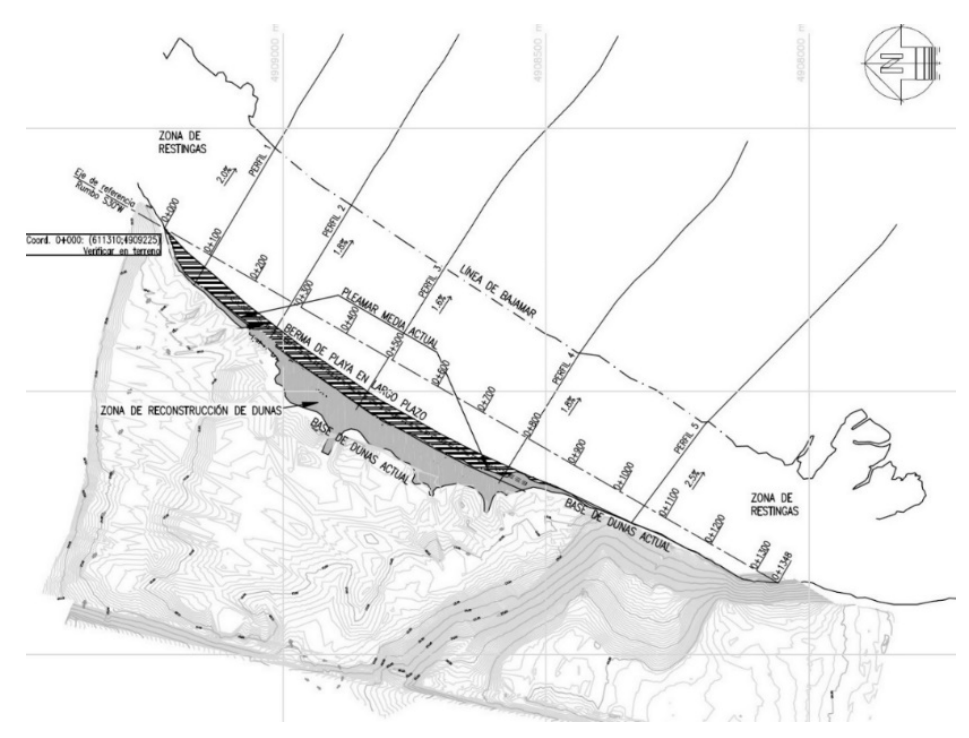

Figure 2: Simulated long term coastal profile, after the sand dunes system restauration. 


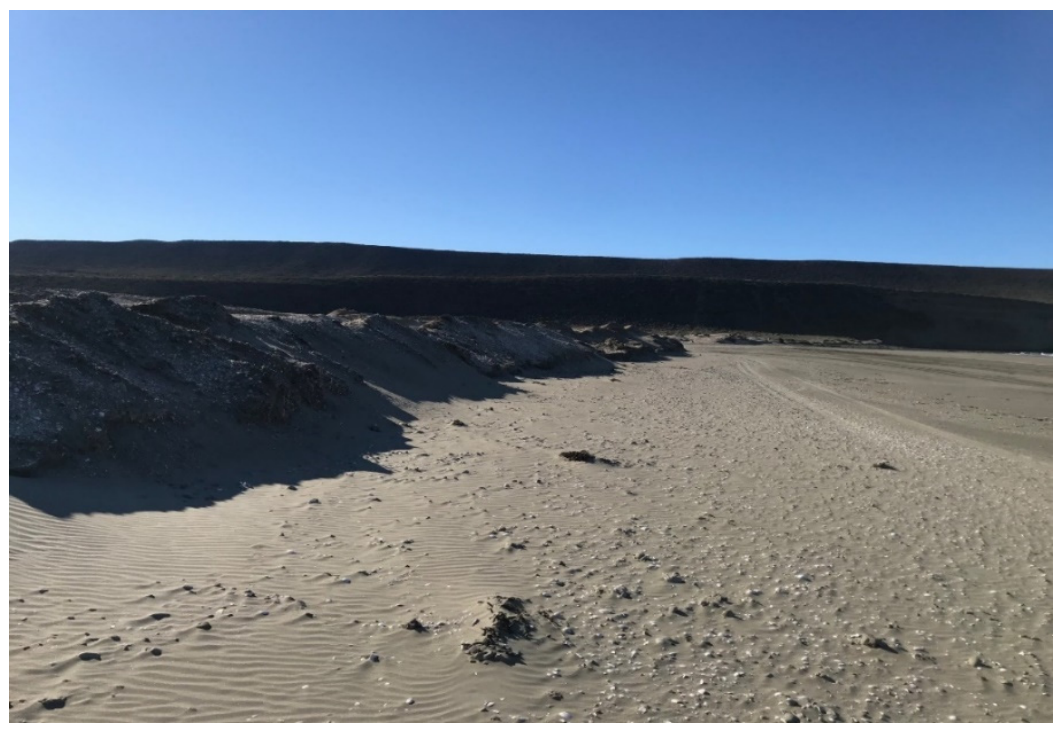

Figure 3: Formed dry beach section recreated after partial restauration of sand dunes.

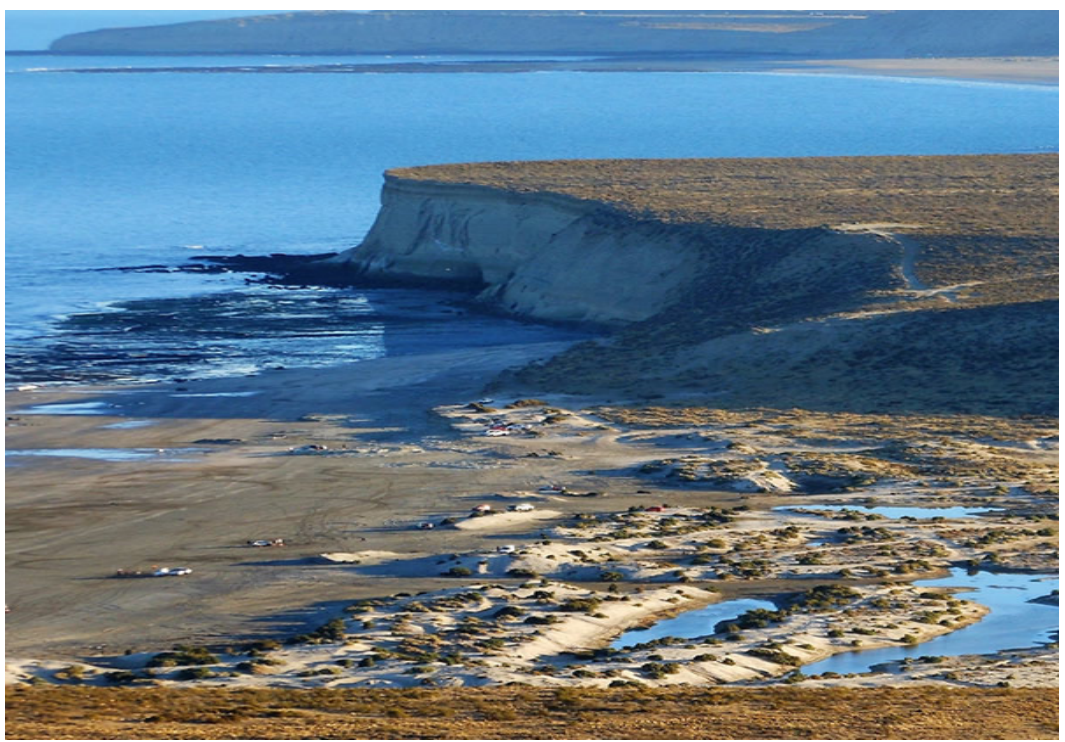

Figure 4: Terrain and coastal condition before restauration, evidencing severe erosion.

\subsection{Terrain Geomorphology and Lagoon}

The dune erosion and the lowering of ground levels were the effects of decades of sand mining for human recreational activities and landfills, in addition to the compaction of the soil by vehicles and human transit. The original line of coastal dunes was degraded and breached resulting in seawater flooding the lower areas during high tides (Fig. 4). 
Several studies were conducted related to littoral transport, erosion, sedimentation, and the design of an artificial fill to recover the dune system and achieve stabilization of the currently deteriorated beach. The project solution approach includes the reconstruction of a line of dunes and the development of a shallow lagoon in an area of depressed topography (Fig. 5). The surface and shape of the lagoon was determined studying the existing lowest contour lines and applying criteria to minimize interventions, soil movements, and impacts to native species. The resulted lagoon shape is shown in Fig. 6, the contour lines and dimensions additionally allow recreational development of nautical activities independent of the sea.

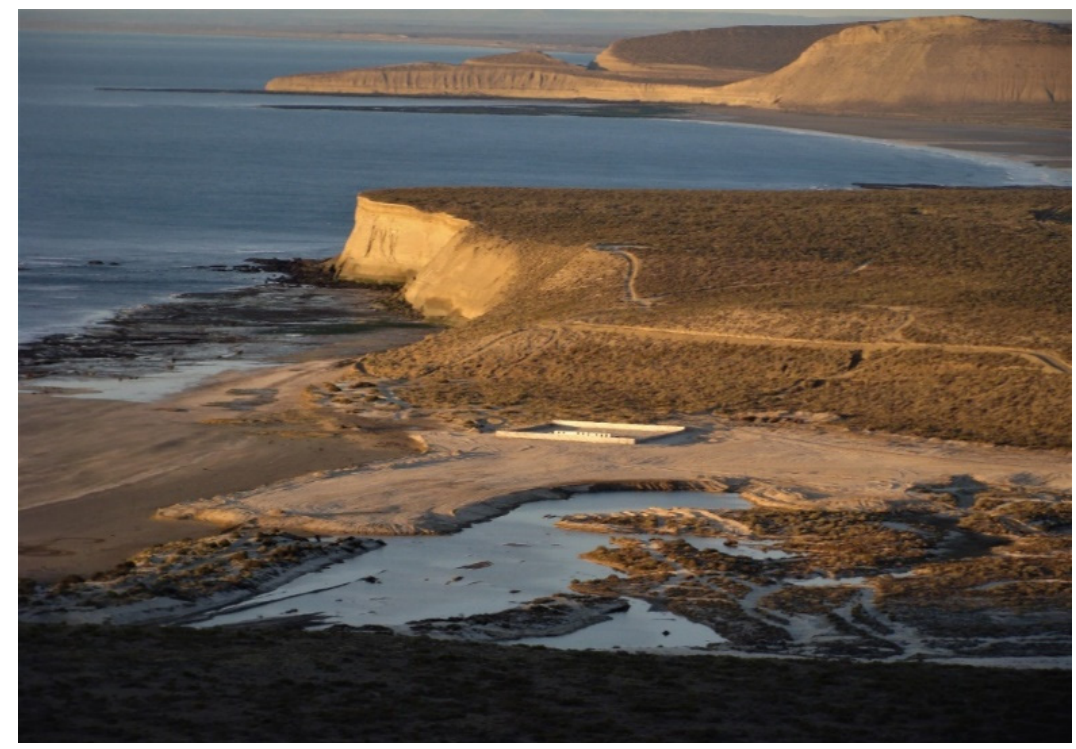

Figure 5: Partial coastal/dune restoration and re-established height levelled coastal terrain.

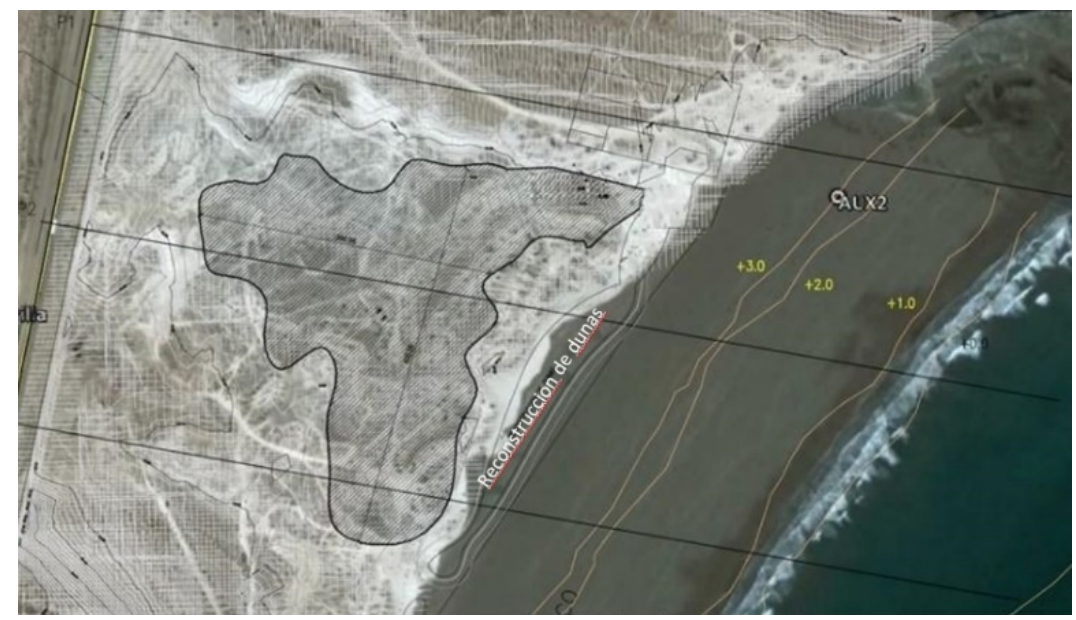

Figure 6: Resulted lagoon contour profile from studying eroded low ground levels. 


\section{URBAN PLANNING - DENSITY AND CONNECTIVITY}

The masterplan is designed respecting the geomorphology of the land - highly eroded as a result of decades of soil extraction by the quarry and land misuse by visitors. A low-density urbanization in Patagonia, promoting sustainable development and its concepts enhancing the natural landscape. It introduces a concept of urban life centred on people in relation to the environment. It promotes smart city/IoT and 24.7 connectivity technologies for the administration of public services, distributed energy generation, onsite treatment of sewage effluents. The model is transferable to public initiatives.

The urban plan design contemplates more than $60 \%$ of land dedicated to landscape reserve purpose and only $25 \%$ of the soil occupation coefficient (SOA) of each property terrain. Overall, combining these parameters, it represents only $10 \%$ of the total soil occupied by constructions, therefore preserving the natural aspect of the land. Additionally, the design of common buildings considers bioclimatic factors such as sun/position/latitude/wind and predominant nature elements, where isolation materials and renewable energy generates the conditions for living only with the necessary. Other strategies to achieve this purpose are green roofs (vegetation) in houses with flat roofs to mimics the effect of land. All this combined is unknown in the region.

The project is aligned with 15 of the 17 objectives of the ONU in sustainable development goals with a focus on objective 11 sustainable cities and communities; objectives $1,3-15,17$.

With respect to mobility within the urbanization, the urban plan design favours mobility by walking and bicycle through dedicate pathways considering all necessary for life will be located within 10 min walk. In the future, in favour of energy transitions, dedicated parking areas with solar chargers will be provided for electric cars or scooters.

\subsection{Project proposal summary}

- Restauration of degraded coastal ecosystem.

- Recycling waste and circular economies with organizations that use materials to reinsert them as transformed materials into the economy, examples are plastic bricks, posts, decks.

- Clean energy, reduction of fossil fuels, renewable energy by solar panels, biodigester from organic waste.

- Employment: produces up to 1000 direct and indirect employees as the project progresses.

- Water scarcity in this arid region of eastern Patagonia will be addressed with different strategies including a desalinization plant.

- Sustainable bioclimatic houses for energy efficiency.

- Landscape and green reserves.

- Educational and sport centres.

- Research and interpretation center to promote ecologic tourism.

- Mobility, urban planning to motivate walk, cycle, and future solar power stations for electric vehicles.

\section{LOCAL OWNERSHIP - BENEFICIARIES}

The direct beneficiaries of the project are mainly two groups. The first are the new owners of parcels that share the vision of a lifestyle in complete integration with the nature with the conditions of dynamic sustainable urbanization. Other beneficiaries are visitors and vacationers who will enjoy access to the beach in proper conditions of hygiene, safety, 
and environmental balance in terms of a public good provided by the project, in contrast to its current deteriorating conditions. The indirect beneficiaries are the groups of the research and academic activities of the regional scientific community and environmental groups that will access the surrounding wild environment in conditions facilitated by currently nonexistent infrastructure accessories. The scientific community will access a dedicated onsite scientific research facility for specialized research work, in contrast with today's practice where certain tests and studies on topics of algae, microalgae, bivalves and biodiversity are disseminated in different locations. Other beneficiaries are local organizations that use recycled materials, to reinsert transformed goods into the economy.

\section{INNOVATION}

The combined multipurpose nature of the project aims to improve the conditions of the surrounding environment. These include access to the beach with adequate conditions for its future preservation, and facilities for research, education, tourism, and sports activities. Some dedicated spaces converted into public goods including the transfer of ownership to the local government to ensure the public condition such as beach access roads, and dedicated parking areas - avoiding today's issue and impact of fuel/oil vehicle's contamination on the beach during low tides. With regards to energy generation, the possibility to reinject distributed generation of electric power into the grid is of interest of the local energy cooperative and treatment plant of sewage effluents with biodigesters, and smart city makes the sustainable condition of the urbanization's elements for the community take ownership and serves as a scalable and replicable case study. Technological innovation and adaptation in current times is an essential pillar [10]. Best practices, lessons learned, procedures, implementation are to be captured and shared with public and government to eventually support policies towards sustainable development as mitigation to climate change.

\section{REPLICABILITY}

This project can be partially or totally replicated as a model of sustainable development. It represents a way to address population growth through sustainable urban development, in areas whereby territory/land distribution regulation issued by local governments is compatible with urban use. Land that is on the outskirts of the main dense sector of cities, in contact with originally natural areas, that however are now damaged due to pressure from human presence and polluting activities. This is applicable when the use of land permits to be developed into urban areas, while still maintaining the connection with the nature and ecology of the place. It is particularly important in areas of vast territory of unused land, and populations concentrated in crowded cities. It aims not to densify an urban sector but to preserve the natural aspects of the land or restoring when it is damaged, improving the quality of land for use by the communities, either residential, recreational, education, scientific, or a combination. It accounts for sustainability concepts such as a specific urban plan design adapted to the geomorphology of the terrain and bioclimatic buildings with architecture adapted to the environment such as weather, sun, latitude, and elements of nature.

\section{GENDER DIVERSIFICATION AND INCLUSION}

Diversity and innovation for a new knowledge economy is an essential part of this project, as a better future cannot be built without equity and integration, or technology and innovation [10]. The inclusive condition of the project is materialized by converting access, use, and preservation of an area of the Patagonian coast - suffering a drastic process of degradation creating the necessary conditions for life in a sustainable manner. It involves transferring key accessibility areas of the infrastructure to the local government, and joint programs for public 
environmental education. Currently, women's content is majority with a strong presence at each level of our organization from the board presidency, communication, engineering, architecture, design, biology, forestry, biochemistry, tourism. We promote empowerment and equal opportunities across our entire organization. Although women have achieved more and better spaces of representation in social, academic, and labour spheres, the plan is to work in this direction, by sponsoring activities to develop women groups. In addition, it is intended to work with marginalized groups in activities such as recycling, promoting small enterprises reinserting their produced goods - such as bricks, outdoor furniture from recycled plastics into the local economy creating true circular economies cycles.

\section{SHARING BEST PRACTICES}

To Improve skills and knowledge transfer to the local community, a series of workshops on themes of sustainable urban development will be organized for the community participation, with invitees from specialists, academia, suppliers. Sessions on specialty themes in line with recommendations to accelerate the reduction of emissions on the following topics:

- Renewable energy generation: SolarPV/Eolic generation (net energy, residential distributed energy; guidance, access to finance programs, minimum generation for residential of $30 \%$ and more than $80 \%$ in common buildings).

- Bioclimatic buildings for thermal isolation.

- Green heating from geothermal energy.

- Recycling and circular economies.

- Biodigesters at urban scale for energy generation.

- Seawater desalinization.

- Mobility: strategies within the urbanization, design of walk/cycle paths, car solar power chargers.

- Smart cities: IoT technology, real time measurement, self-learning processes.

- Lessons and experiences shared through communication material, publications, academic papers in relevant events.

\section{CONCLUSIONS}

Although at a small scale, the sustainable mixed urban development project described addressing issues such as restoration, clean energy generation reducing fossil fuel dependency, waste, and water management - could provide a positive impact for NDC implementation at country level. Its replication and scalability will represent the possibility of building capacity at a global scale approach. Therefore, the opportunity with a small contribution to produce a positive global impact. The project aims for capacity building to support energy transitions towards low emissions and economic, ecological, resilient, and inclusive recovery of communities.

It becomes critical to relate at country level climate risk management and investment/finance programs to tackle risk mitigation, as ignoring today's issues will exacerbate conditions for further deterioration of economies, and people's wellbeing.

COVID 19, has placed communities under stress, as evidenced by a correlation between urban environment and health. Therefore, the quality of ecosystems and the urban environment impacts hygiene, safety, public health. Ultimate balance between demographics reduces pressure on the natural environment improving conditions of sustainable urbanizations and greater protection of biodiversity.

Investment in the reconstruction of sand dunes restoring an ecological system is considered of high interest, unique on the Atlantic coast. 
Future mechanisms of cooperation will be beneficial, ranging from funding to technical assistance, and participation in programs with all players from public governance to the private sector.

\section{ACKNOWLEDGEMENTS}

We would like to thank Refugio de los Lobos S.A. for their permission to publish this paper, and all discipline specialists that contributed to this work.

\section{REFERENCES}

[1] Clark, P. et al., Consequences of twenty-first-century policy for multi-millennial climate and sea-level change. Nature Climate Change, 6, pp. 360-369, 2016. https://doi.org/10.1038/nclimate2923.

[2] Monasterolo, I., Roventini, A. \& Foxonc, T., Uncertainty of climate policies and implications for economics and finance: An evolutionary economics approach. Ecological Economics, 163, pp. 177-182, 2019. https://doi.org/10.1016/j.ecolecon.2019.05.012.

[3] Barbier, E.B., Greening the post-pandemic recovery in the G20. Environmental and Resource Economics, 76, pp. 685-703, 2020. https://doi.org/10.1007/s10640-020-00437-w.

[4] Hagemann, M. et al., Roadmap for the power supply sector in Argentina implications of ambitious climate action for policy and investment, 2019. https://repository.tudelft.nl/view/tno/uuid\%3A836e8f0f-2a1a-4b35-8a479e989ee985c8.

[5] Massera, C., Modelo ambiental con Sistemas de Información Geográfica aplicado a la gestión de riesgo de desastres urbano: el caso Comodoro Rivadavia (Chubut, Argentina), 2008-2017, 2018. http://repositoriodigital.uns.edu.ar/handle/123456789/4408.

[6] Martínez, N. \& Porcelli, M., Análisis del marco legislativo argentino sobre el régimen de fomento a la generación distribuida de energía renovable integrada a la red pública. Lex Social: Revista de Derechos Sociales, 8(2), pp. 179-198, 2018. www.upo.es/revistas/index.php/lex_social/article/view/3490.

[7] Dolan, A. \& Walker, I., Understanding vulnerability of coastal communities to climate change related risks. Journal of Coastal Research, 39, pp. 1316-1323, 2006. www.jstor.org/stable/25742967.

[8] Beeskow, A.M., Del Valle, H.F. \& Rostagno, C.M., Los sistemas fisiográficos de la región árida y semiárida de la provincia del Chubut. Centro Nacional Patagónico Consejo Nacional de investigaciones científicas y técnicas, Pto Madryn Chub, 16 pp., 1987.

[9] Matteuci, M. \& Colma, M., El papel de la vegetación como indicadora del ambiente. Sistemas Ambientales Complejos: Herramientas de Análisis Espacial, EUDEBA, pp. 293-320, 1998.

[10] Cooke, P., The role of research in regional innovation systems: new models meeting knowledge economy demands. International Journal of Technology Management, 28, pp. 1741-5276, 2004. https://doi.org/10.1504/IJTM.2004.005307. 